\title{
EL FRAGMENTO 48 DEL PROTRÉPTICO DE ARISTÓTELES A LA LUZ DE SOBRE LAS IDEAS: ¿VOCABULARIO PLATÓNICO O CONCEPCIONES PLATÓNICAS?
}

\author{
Claudia Seggiaro* * Universidad de \\ Buenos Aires. \\ CONICET.
}

\begin{abstract}
RESUMEN: El objetivo de este trabajo es analizar el fragmento 48 del Protréptico teniendo como telón de fondo alguna de las críticas que Aristóteles presentó contra los principios platónicos en Sobre las Ideas. Creemos que, si bien el fragmento 48 del Protréptico tiene cierta reminiscencia platónica, su lectura, a la luz de Sobre las Ideas, nos permite sostener que, de haber defendido la teoría platónica de las Ideas en el primer escrito, Aristóteles habría caído en una inconsistencia, pues estaría expuesto a las mismas críticas que realiza contra esos principios en obras relativamente contemporáneas. Por otra parte, consideramos que quienes persisten en creer que el fragmento 48 del Protréptico es un testimonio de que Aristóteles defendió tal teoría incurren en la misma crítica que el estagirita realiza contra los platónicos en el argumento a partir de la ciencia de Sobre las Ideas, pues afirman más de lo que el texto permite concluir.
\end{abstract}

PALABRAS CLAVES: Protréptico; Sobre las Ideas; argumento a partir de las ciencias; teoría platónica de las Ideas.

\section{THE FRAGMENT 48 OF ARISTOTLE'S PROTREPTICUS IN THE LIGHT OF ON IDEAS: PLATONIC VOCABULARY OR PLATONIC CONCEPTIONS?}

\begin{abstract}
The aim of this work is to examine the fragment 48 of the Protepticus, taking as background the criticism that Aristotle presented against the platonic principles in On Ideas. We believe that, although the fragment 48 of the Protepticus has some platonic reminiscence, its reading, in the light of On Ideas, allows us to maintain that if he had supported the Platonic theory of Ideas in the first writing, Aristotle would have fallen down in an inconsistency, since it would be exposed to the same critiques that it realizes against these principles in relatively contemporary works. On the other hand, we consider that those who persist in believing that Fragment 48 of the Protepticus is a testimony that Aristotle defended such theory incur the same criticism that the stagirite performs against
\end{abstract}


the platonists in the argument from the science of On Ideas, because they affirm more than the text allows to conclude.

KEYWORDS: Protrepticus; On Ideas; argument from the sciences; platonic theory of Ideas.

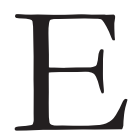
1 fragmento $48^{1}$ del Protréptico es uno de los más controvertidos. ${ }^{2}$ La concepción de la filosofía como la ciencia de lo que es "primero en sí mismo" (autà tà prôta) y no de objetos de segundo o tercer orden ha hecho que la exegesis de este fragmento sea una cuestión problemática y, por lo tanto, objeto de debate entre los intérpretes. El vocabulario aparentemente platónico ha despertado entre los estudiosos del texto la sospecha de que el Protréptico fue escrito en un período platónico del pensamiento de Aristóteles, en el cual habría apoyado la teoría de las Ideas defendida por Platón. ${ }^{3}$

No obstante, la datación de algunos escritos en el mismo período o en un período muy próximo al Protréptico, como Metafísica I 9 y Sobre las ideas, en los que Aristóteles critica explícitamente la teoría platónica de las Ideas, pone en cuestión esta tesis. Dado esto, la pregunta es: ¿por qué Aristóteles se vale de este lenguaje que genera reminiscencias platónicas?; ¿qué concepciones refleja la utilización de este léxico?; ¿podemos sostener que Aristóteles se vale de un vocabulario platónico para expresar concepciones no platónicas?; más aun, ¿este vocabulario es exclusivamente platónico?

Sobre la base de estos interrogantes, el objetivo de nuestro trabajo es examinar el fragmento 48 del Protréptico teniendo como telón de fondo alguna de las críticas que Aristóteles presentó contra los principios platónicos en Sobre las Ideas. Creemos que, si bien el fragmento 48 tiene cierta reminiscencia platónica, su lectura a la luz de los escritos contemporáneos al Protréptico, tales como los dos primeros libros de la Metafísica, Ética Eudemia y Ética Nicomáquea, nos permite sostener una continuidad entre esta obra y el resto del corpus, al menos en lo

\footnotetext{
${ }^{1}$ Para las citas y numeración de los fragmentos del Protréptico seguiremos la edición de Düring (1961).

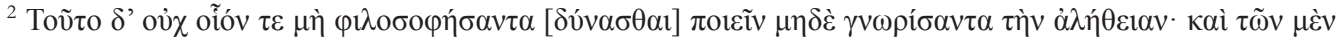

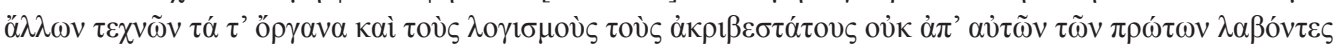

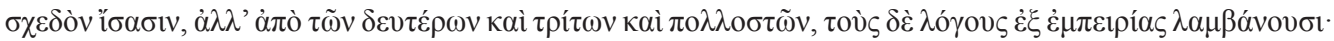

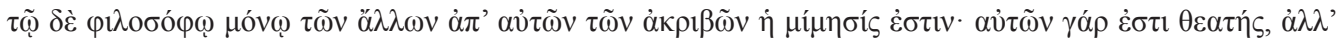

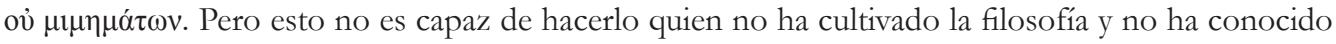
la verdad. Y, en las demás artes, no alcanzan el saber íntegramente, al no obtener los instrumentos y los razonamientos más exactos de objetos primeros en sí mismos, sino de objetos segundos, terceros o aun más alejados, y extraen sus razonamientos de la experiencia. A diferencia de los demás, solo en el caso del filósofo tiene lugar la imitación a partir de objetos exactos en sí mismos. Pues él los contempla en sí mismos y no en sus imitaciones. Jámblico, Protréptico X 54. 6-14. Trad. Vallejo Campos. ${ }^{3}$ Siguiendo un orden cronológico, algunos autores que desde la aparición del trabajo de Jaeger (1923) en adelante sostuvieron esta tesis son: Bignone (1936 edición aumentada 1976), de Vogel (1960, p. 248-256), Guthrie (1981, p. 90), Vallejo Campos (1994, p. 71-90). Sin embargo, este ultimo autor considerará posteriormente que afirmar o negar que Aristóteles haya sostenido la teoría de las Ideas es igualmente problemático (Vallejo Campos, 2005, p. 14-15). Case (1996, p. 4).
} 
que a la concepción epistemológica se refiere. A tales efectos, dividiremos el trabajo en tres partes. En la primera, nos ocuparemos de la datación de las obras empleadas en el trabajo: el Protréptico, y Sobre las Ideas. La finalidad de este análisis es dar cuenta de la relevancia de recurrir a este último escrito para resolver los interrogantes presentados en relación con el fragmento 48 del Protréptico. En la segunda parte, analizaremos algunas de las críticas a la teoría de las Ideas que aparecen en Sobre las Ideas. Debido a la complejidad que este análisis implica, no nos detendremos en todas las críticas que Aristóteles presenta en esta obra, sino solo en aquellas que pueden resultar significativas a la luz del fragmento 48 del Protréptico, esto es, las relativas al argumento que parte de las ciencias. Creemos que utilizar un texto datado en el mismo período es buena estrategia para demostrar que Aristóteles no podría haber defendido la teoría de las Ideas en el Protréptico, pues, de lo contrario, habría caído en una inconsistencia. Si bien de Düring en adelante la tendencia general de los intérpretes suele ser negar que Aristóteles haya sostenido la teoría platónica de las Ideas, ninguno de los trabajos que hemos analizado se ha centrado en refutar esta tesis teniendo como clave hermenéutica las críticas aristotélicas a esta teoría. En general se han basado en la cronología de los escritos y, por lo tanto, en la contemporaneidad entre las críticas a la teoría platónica de las Ideas y la redacción del Protréptico, lo cual, si bien es relevante, no muestra el problema de fondo que la interpretación a rechazar supone. Por nuestra parte, creemos que quienes sostienen que hay teoría de las Ideas en el fragmento 48 incurren en la crítica que Aristóteles les hace a los platónicos: dicen más de lo que el texto autoriza a decir, razón por la cual están sujetos a la misma refutación, pues no son concluyentes respecto de lo que quieren demostrar.

\section{Datación DE LAS ObRas ARISTOTÉLICAS}

En general se suele considerar que tanto el Protréptico como Sobre las Ideas son obras tempranas. Hay un consenso relativamente unánime acerca de que el Protréptico fue escrito durante el período de permanencia de Aristóteles en la Academia, entre 353 y 351 a.C. Los estudiosos del texto consideran que fue redactado después de obras como el Grilo y el Eudemo, pues estiman que Aristóteles lo escribió influido por la controversia entre la escuela platónica y la escuela de Isócrates. Por tal motivo, suelen considerar que el Protréptico era una respuesta a la Antídosis de Isócrates, texto que habría sido escrito alrededor del 352 a. C.

El único que ha discutido esta datación de la obra es Schneeweiss. ${ }^{4}$ Desde su perspectiva, esta datación carece de un fundamento histórico real que permita apoyarla con seriedad. Este autor, de hecho, tiende a considerar que el Protréptico fue un escrito de madurez. Si bien Schneeweiss no pone en cuestión el argumento que fundamenta la hipótesis arriba expuesta, considera que es apresurado inferir la datación del Protréptico a partir del conocimiento de cuándo fue escrito el texto de Isócrates que incentivó su redacción. ${ }^{5}$ Ahora bien, con este argumento, Schneeweiss tampoco da elementos concluyentes para sostener

\footnotetext{
${ }^{4}$ Schneeweiss (2005, p. 29).

${ }^{5}$ Schneeweiss (2005, p. 29-30).
} 
que el Protréptico no es un diálogo de juventud. Si bien sus interrogantes pueden ser legítimos, sirven para poner en tela de juicio cuándo fue escrita la obra, pero no para hacer una datación. Es verdad que ni en los testimonios ni en los fragmentos conservados del Protréptico se hace mención de un supuesto debate con Isócrates en un momento determinado. El interlocutor de Aristóteles sólo se puede reconstruir en forma indirecta a través de las concepciones esbozadas en los pocos pasajes que hemos conservado de la obra. No obstante, el hecho de poder realizar esta reconstrucción, sumado a que durante la permanencia de Aristóteles en la Academia existía un debate de público conocimiento entre Isócrates y Platón, nos predispone a aceptar la datación temprana de la obra en cuestión más que su datación tardía.

La datación de Sobre las Ideas es más conflictiva. Si bien es considerado por la mayor parte de los intérpretes como un escrito temprano, hay discusiones a propósito de cuándo fue redactado: si es una obra del período académico o posterior a la muerte de Platón. Esta discusión pone en evidencia cómo la interpretación de la evolución del pensamiento del estagirita ha influenciado en la datación de su obra, a tal punto que algunos autores, ${ }^{6}$ que suponen que Aristóteles ha evolucionado de un período platónico a uno netamente aristotélico, consideran que es posterior a la muerte de Platón, mientras que otros autores, que sostienen que Aristóteles siempre ha sido adverso a la teoría platónica de las Ideas, ${ }^{7}$ estiman que es de período académico.

La confrontación entre Metafísica I 9 y Sobre las Ideas nos permiten sostenes que las objeciones contra las concepciones de los platónicos presentadas en el primer escrito son una versión más abreviada de la crítica que Aristóteles habría realizado a la teoría de las Ideas en una obra un poco más antigua que, por el tenor de los argumentos esgrimidos en ambos textos, debería ser Sobre las Ideas. Por tal motivo, Berti ${ }^{8}$ cree que esta última obra se habría escrito en 357 a.C. Cherniss, 'incluso, estima que es contemporánea al Parménides de Platón.

Zanatta ${ }^{10}$ considera que el debate en torno a la teoría de las Ideas en el seno de la institución platónica permite ubicar a Sobre las Ideas en el período académico. ${ }^{11}$ Sobre las Ideas era "la contribución ofrecida por Aristóteles a esa discusión. Una contribución esencial por lo precisa y por el modo mismo en que (...) está estructurada: primero la reconstrucción de los argumentos por los cuales era válido postular la teoría de las Ideas y a continuación las críticas del estagirita". ${ }^{12}$ En una línea de lectura análoga, Fine ${ }^{13}$ piensa que la relación entre

\footnotetext{
${ }^{6}$ Entre estos autores podemos citar a Jaeger (1993, p. 109ss.), Guthrie (1993, p. 91) y Case (1996, p. 4). Según este autor, esta presencia de las teorías platónicas en escritos como el Eudemo y el Protréptico "es quizás una razón por la cual Cicerón, que conoció los primeros escritos de Aristóteles, dijo que no había diferencia entre la Academia y los peripatéticos" (1996, p. 5).

${ }^{7}$ Un claro ejemplo es Düring (1990, p. 921).

${ }^{8}$ Berti (1997, p. 131ss.).

${ }^{9}$ Cherniss (1944, p. 488-494).

${ }^{10}$ Zanatta (2010, p. 220).

${ }^{11}$ Fine (2004, p. 39).

${ }^{12}$ Zanatta (2010, p. 220).

${ }^{13}$ Fine (2004, p. 41).
} 
los argumentos presentados en Sobre las Ideas y los diálogos platónicos como el Timeo o el Filebo nos permite decir que hay una afinidad entre la obra aristotélica en cuestión y estos últimos escritos platónicos. No obstante, esta autora afirma que es imposible garantizar que Aristóteles haya escrito Sobre las Ideas bajo la influencia de estos últimos diálogos platónicos y que, por lo tanto, sea un escrito contemporáneo o posterior a ellos. Desde su perspectiva, el Sobre las Ideas fue escrito antes que el Timeo o el Filebo. Las coincidencias entre algunas de las temáticas allí abordadas responden, entre otras cosas, a esto. ${ }^{14}$ Según Cardullo, ${ }^{15}$ Sobre las Ideas era una obra en la que Aristóteles confronta la teoría de las Ideas, pero en la que perdura aun una fuerte influencia platónica. Como señala esta autora, en este mismo período Aristóteles estaba empezando a desarrollar algunas de sus más importantes doctrinas sobre la argumentación lógica y la predicación, así como las nociones de homonimia y sinonimia, vinculadas con ellas. Ya sostenía una nueva concepción del universal y había presentado su tabla de las categorías. No obstante, para Cardullo, "el 'punto de inflexión' todavía no se ha realizado plenamente". ${ }^{16}$

Sobre la base de lo analizado, coincidimos con la mayor parte de los intérpretes que sostienen que Sobre las Ideas debió ser escrito en el período académico. Un elemento importante a tener en cuenta es que en Física I, libro respecto del cual hay un acuerdo unánime que fue redactado en un período temprano, Aristóteles cita a Sobre la filosofía, texto en el cual critica explícitamente la teoría platónica de las Ideas. Más allá de que la redacción del Protréptico sea anterior o posterior a Sobre las Ideas, este dato es una evidencia de que desde el comienzo de su producción escrita Aristóteles tenía fuertes reparos respecto de la teoría de los principios defendida por Platón, razón por la cual, de haberla sostenido en su Protréptico, habría caído en graves inconsistencias.

\section{Algunas consideraciones Sobre el argumento a Partir de las Ciencias DE SOBRE LAS IDEAS}

En Sobre las Ideas Aristóteles desarrolla muchas de las problemáticas que encuentra en la metafísica platónica. En esta obra, Aristóteles expuso los argumentos por los cuales los platónicos postularon las Ideas valiéndose de la noción de ciencia y los motivos por los cuales considera que estas pruebas no son concluyentes. Nos interesa este planteo en particular porque en el fragmento 48 del Protréptico el estagirita define la filosofía como el conocimiento de lo que "es en sî", razón por la cual algunos autores han creído encontrar la defensa aristotélica de la teoría platónica de las Ideas. Mientras que en Sobre las Ideas Aristóteles sostiene que los platónicos para postular la necesidad de la existencia de las Ideas parten de la premisa de que la ciencia es el conocimiento de lo que siempre es y no de que es lo particular y contingente, en relación con el Protréptico, quienes creen encontrar la presencia de esta teoría, toman como punto de partida que existe lo bueno y bello en

\footnotetext{
${ }^{14}$ Fine (2004, p. 41).

${ }^{15}$ Cardullo (2002, p. 160).

${ }^{16}$ Cardullo (2002, p. 161).
} 
sí mismo (fragmento 48-49) y que la ciencia consiste en el conocimiento de esto último y no de imitaciones, para luego concluir que Aristóteles tuvo que haber defendido en este escrito la existencia de los principios antes mencionados. Como consecuencia de esto, el análisis cruzado del argumento basado en las ciencias de Sobre las Ideas y del fragmento 48 del Protréptico resulta relevante para confirmar o refutar la tesis de quienes quieren ver en Aristóteles la presencia de la teoría platónica.

Una de las versiones del argumento a partir de la ciencia comienza del siguiente modo:

Los platónicos se sirvieron de las ciencias de varias maneras para establecer las Ideas, como dice Aristóteles en el primer libro de su obra Sobre las Ideas. Los argumentos que parece recordar en este momento son los siguientes. Si toda ciencia realiza su función haciendo referencia a algo, único e idéntico, y no en relación con ninguna de las cosas particulares, debería haber para cada ciencia alguna cosa, aparte de las sensibles, que sea eterna y paradigma de las cosas que se generan en el ámbito de cada ciencia. Y tal es la Idea. (Ross, 3; Gigon, 118, 3. Alejandro de Afrodisia, Comentario de la Metafísica de Aristóteles 79, 3-8. Trad. Vallejo Campos). ${ }^{17}$

Es importante destacar que el extracto que transcribimos nos ha llegado a través de Alejandro de Afrodisia. El contexto en el cual Alejandro cita Sobre las Ideas es su comentario al libro primero de la Metafísica, más precisamente, el capítulo 9, esto es, el capítulo en el cual Aristóteles retoma la teoría platónica de los principios, formulando algunos de los problemas que desde su perspectiva presentaba.

El fragmento de Sobre las Ideas parte del supuesto de que, si hay ciencia, esta no puede ser de lo múltiple y sujeto al devenir. ${ }^{18}$ Este supuesto, al cual tanto un platónico ${ }^{19}$ como un aristotélico ${ }^{20}$ adherirían, presupone que el conocimiento es de aquello que es siempre idéntico a sí mismo y permanece invariable. Lo sensible es particular y, por esto mismo, contingente. ${ }^{21}$ Por esta razón, de lo que es sensible no puede haber ciencia. Tal como lo

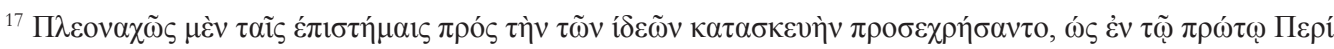

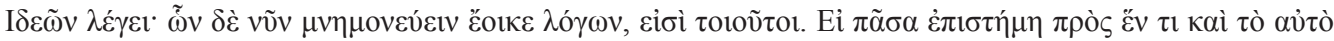

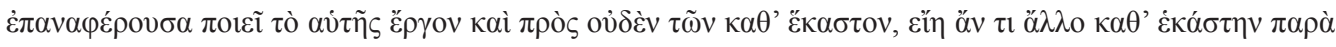

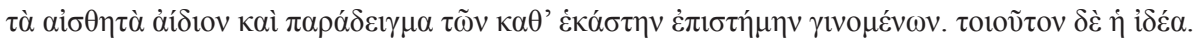

${ }^{18}$ Esto aparece en la segunda formulación del argumento a partir de la ciencia presentado por Alejandro de Afrodisias (Comentario de la Metafísica de Aristóteles 79, 8-1 1).

19 República VI 484b; VII 533d- 534a.

${ }^{20}$ Metafísica I 1, 981a15-25. Como lo indica Berti (2008, p. 24), "El carácter de necesidad, propio de la ciencia entendida en sentido aristotélico, es frecuentemente indicado por Aristóteles mediante la afirmación de que la ciencia es conocimiento de cosas que existen siempre: esto no significa que todos los objetos de la ciencia sean sustancias eternas, como eran para Platón los objetos de la matemática y para Aristóteles los astros y sus motores, sino que son eternos los nexos entre ciertos objetos y ciertas propiedades suyas, de las cuales se tiene precisamente ciencia”.

${ }^{21}$ Platón República 479 a.
} 
indica Viano, ${ }^{22}$ las diferentes formulaciones del argumento a partir de las ciencias parten en las siguientes premisas:

1) toda ciencia tiene un objeto propio y unitario, que no es ninguno de los individuos particulares, sino un modelo eterno o paradigma;

2) los individuos son infinitos e indeterminados, mientras las ciencias versan sobre lo definido, por lo tanto, como los objetos de la ciencia existen, debe existir algo que está más allá de los individuos;

3) la medicina no es una ciencia de la salud particular sino de la salud en sí, del mismo modo que la geometría y demás ciencias.

De estos argumentos se desprende que, si hay conocimiento, debe haber algo aparte de lo sensible, algo que es único e idéntico y esto debe ser las Ideas. Desde la perspectiva de Berti, ${ }^{23}$ no hay en los diálogos platónicos un argumento en favor de la existencia de las Ideas que apele a la ciencia en forma directa. Sin embargo, Berti cree encontrar en el argumento aristotélico una remisión al Teeteto, diálogo del período en el cual Aristóteles estaba ingresando a la Academia. La negación platónica de que la ciencia pueda ser percepción (151d-186e) u opinión (187a-201c) es la clave por la cual Berti cree ver una vinculación entre el Teeteto y el argumento basado en la ciencia de Sobre las Ideas.

Sin embargo, para Fine el diálogo que presenta el argumento basado en la ciencia con la conclusión que Aristóteles supone, esto es, la existencia de Ideas trascendentes, es República, más específicamente el libro V. ${ }^{24}$ Dicho argumento estaría en la base de las siguientes palabras de Sócrates:

- Admitido esto, podré decir que me hable y responda aquel valiente que no cree que haya algo Bello en sí, ni una Idea de la Belleza en sí que se comporta siempre del mismo modo, sino muchas cosas bellas; aquel amante de espectáculos que de ningún modo tolera que se le diga que existe lo Bello único. Lo Justo, etc. "Excelente amigo", le diremos, "de estas múltiples cosas bellas, ¿hay alguna que no te parezca fea en algún sentido? ¿Y de las justas, alguna que no te parezca injusta? y de las santas una que no te parezca profana?" - No, necesariamente las cosas bellas han de parecer en algún sentido feas, y así como cualquier otra de las que preguntas $(479 a-b){ }^{25}$

\footnotetext{
${ }^{22}$ Viano (1980, p. 214).

${ }^{23}$ Berti (1997, p. 136).

${ }^{24}$ Desde la perspectiva de Mohr (1977, p. 232), el diálogo en el cual Platón implementa este tipo de argumento es el Político (284a-b). Este autor considera que este diálogo es la fuente del argumento a partir de las ciencias expuesto en Metafísica I 9 y en Sobre las ideas.

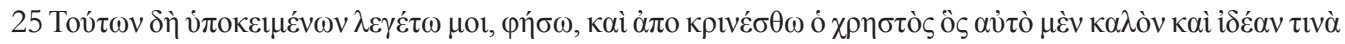

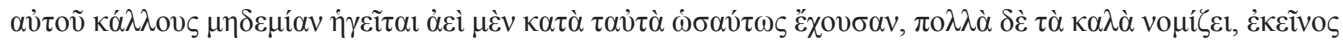

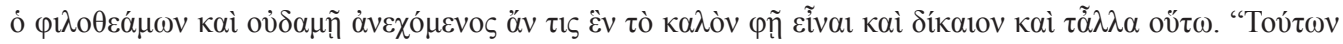


El argumento de Sócrates comienza con una reducción al absurdo que consiste en considerar qué sucedería si admitiéramos que no hay algo bello, justo o bueno en sí mismo, esto es, si solo aceptásemos la existencia de las cosas sensibles. De la admisión de esta tesis, lo que se desprende es que deberíamos admitir que las cosas son al mismo tiempo bellas y no bellas, justas e injustas, es decir, deberíamos conceder que las cosas pueden poseer propiedades contrarias simultáneamente. El inconveniente frente a esta conclusión es presentado por Sócrates en 479e:

En tal caso, de aquellos que contemplan las múltiples cosas bellas, pero no ven lo Bello en sí ni son capaces de seguir a otro que los conduzca hacia él, o ven múltiples cosas justas, pero no lo Justo en sí, y así con todo, diremos que opinan acerca de todo pero no conocen nada de aquello sobre lo que opinan.

- Necesariamente.

- ¿Qué diremos, en cambio, de los que contemplan las cosas en sí y que se comportan siempre del mismo modo, sino que conocen, y que no opinan?

- También es necesario esto. ${ }^{26}$

Quienes niegan la existencia de las Ideas y creen que solo existe lo particular sensible niegan el conocimiento, razón por la cual podrán tener opinión, pero no verdadera ciencia. Para Sócrates, el conocimiento es de lo que es, pero las cosas sensibles, tal como lo vimos más arriba, no solo están sujetas al devenir, sino que pueden recibir atributos contrarios. Por tal motivo, Sócrates considera que están entre el ser y el no ser, ya que no parecen tan oscuras como el no ser, pero tampoco son tan luminosas como el ser. La definición de conocimiento y sus condiciones de posibilidad son lo que lleva a los interlocutores a admitir que, contrariamente a lo que piensa el amante de espectáculos, debe existir lo bello, lo bueno y justo en sí y solo esto puede ser objeto de epistéme. ${ }^{27}$

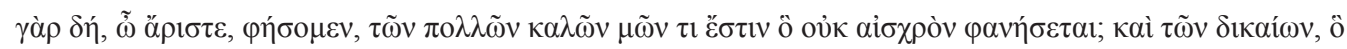

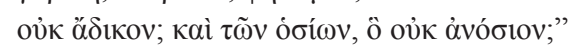

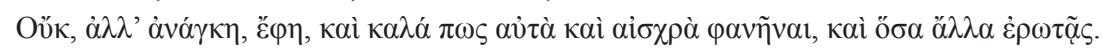

El mismo argumento aparece esbozado en Fedón 100c-e.

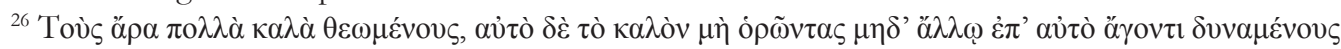

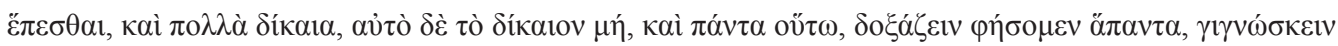
$\delta \dot{\varepsilon} \tilde{\omega} v \delta o \xi \dot{\alpha} \zeta o v \sigma ı v o v ̉ \delta \varepsilon ́ v$.

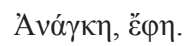

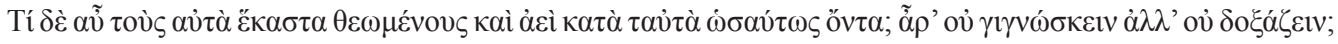

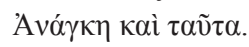

${ }^{27}$ República 477a-b. 
Otro de los diálogos en el cual, coincidimos con Fine, ${ }^{28}$ Platón utiliza el argumento basado en la ciencia es el Menón. En este diálogo, al buscar la definición de la virtud, Sócrates sostiene:

SOC. - Parece que he tenido mucha suerte, Menón, pues buscando una sola virtud he hallado que tienes un enjambre de virtudes en ti para ofrecer. Y a propósito de esta imagen del enjambre, Menón, si al preguntar yo qué es una abeja cuál es su naturaleza, me dijera que son muchas y de todo tipo, qué me contestarías si continuara preguntándote: “¿Afirmas acaso que es por ser abejas por lo que son muchas, de todo tipo y diferentes entre sí? ¿ंO bien, en nada difieren por eso, sino por alguna otra cosa, como la belleza, el tamaño o algo por el estilo?” Dime, ¿qué contestarías si te preguntara eso?

MEN. - Esto contestaría: que en nada difieren una de la otra, en tanto que abejas.

SOC. - y si después de eso te preguntara: Dime, Menón, aquello precisamente en lo que en nada difieren, por lo que son todas iguales, ¿qué afirmas que es? ¿Me podrías decir algo?

MEN. - Podría.

SOC. - Pues lo mismo sucede con las virtudes. Aunque sean muchas y de todo tipo, todas tienen una única y misma forma, por obra de la cual son virtudes y es hacia ella hacia donde ha de dirigir con atención su mirada, quien responda a la pregunta y muestre, efectivamente, en qué consiste la virtud. ¿O no comprendes lo que digo? (Menón 72a-c. Trad. Olivieri). ${ }^{29}$

La diferencia entre República y este escrito es que el Menón es un diálogo relativamente temprano, esto es, del período de transición entre el llamado período de Juventud y de madurez, razón por la cual presuponen un planteo metafísico distinto: no hay evidencia en

\footnotetext{
${ }^{28}$ Fine $(2004$, p. 89ss)

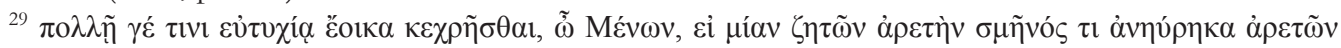

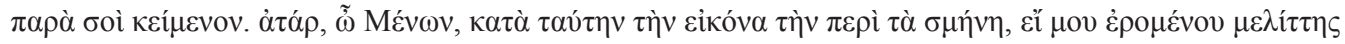

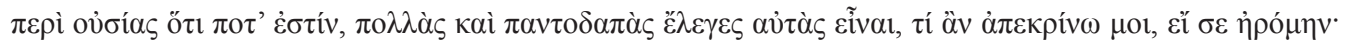

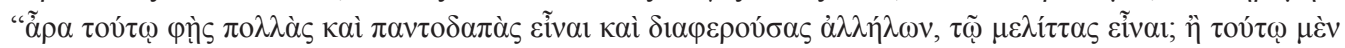

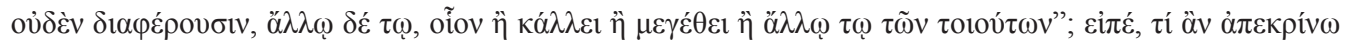

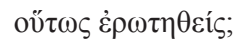

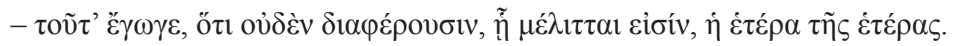

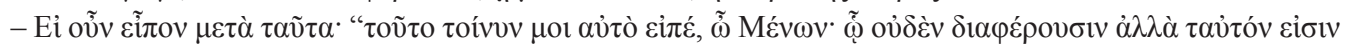

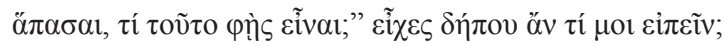

$-\varepsilon$ है $\omega \gamma \varepsilon$.

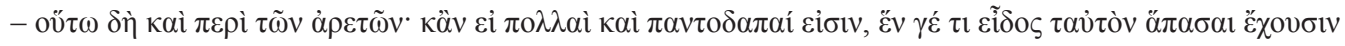

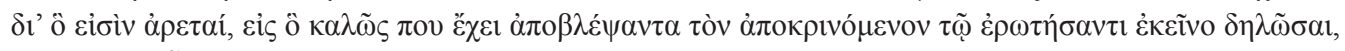

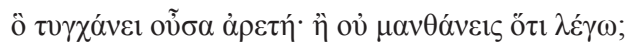


esas obras de que Platón haya defendido la teoría de las Ideas. ${ }^{30}$ En el Menón el argumento es utilizado para sostener que solo tenemos conocimiento de las cosas cuando podemos proporcionar su definición, lo cual equivale a decir que solo tenemos ciencia cuando sabemos cuál es la esencia de algo y no solamente cuando proporcionamos una caracterización. Ahora bien, la esencia es identificada con el rasgo que permite agrupar a un conjunto de individuos bajo un mismo género, esto es, la propiedad distintiva de ese grupo de cosas. Para saber qué son las cosas se debe conocer esa propiedad esencial ${ }^{31}$ que hace que cada uno de esos múltiples individuos sea lo que es. Esto último que es llamado por Sócrates paradigma o forma (eîdos) no es transcendente en el sentido de separado, ${ }^{32}$ como sí lo son las Ideas en los diálogos de madurez, razón por la cual, si bien en este diálogo, al igual que República, se usa el argumento basado en las ciencias, no se arriba a las mismas conclusiones y, por lo tanto, no está expuestos a la refutación aristotélica. ${ }^{33}$ Para Aristóteles:

tales argumentos no demuestran lo que se proponen, que es la existencia de las Ideas, sino que demuestran la existencia de ciertas cosas aparte de las particulares y sensibles. Pero del hecho de que haya ciertas cosas aparte de las particulares no se sigue de ninguna manera que éstas sean Ideas, pues aparte de las cosas particulares están los objetos comunes, y las ciencias, según decimos nosotros, tratan de ellos. (Sobre las Ideas, en Alejandro de Afrodisia, Comentario a la Metafísica 79, 15-19. Trad. Vallejo Campos). ${ }^{34}$

El análisis de los pasajes seleccionados nos permite concluir que en algunos casos Platón utiliza el argumento basado en las ciencias para dar cuenta de la necesidad de un eîdos inmanente o de la propiedad distintiva de las cosas. ${ }^{35}$ Sin embargo, en otros casos con ese mismo argumento pretende defender la teoría de las Ideas, esto es, principios trascendentes de las cosas y, en este sentido, su causa ontológica y gnoseológica. Este doble empleo pone en evidencia que al usarlo en esta segunda instancia no puede ser concluyente respecto de lo que quiere demostrar, ya que el mismo argumento le sirve también cuando pretende dar cuenta solo de la existencia de los koiná de las cosas particulares. Como consecuencia de esto, mediante ese argumento solo probaría la necesidad de que todas las cosas compartan una

\footnotetext{
${ }^{30}$ Ross (1993, p. 11ss) considera que en los diálogos tempranos la teoría de las Ideas está germinalmente formulada.

${ }^{31}$ Véase Bravo (2009, p. 53-54).

${ }^{32}$ Fine (2004, p. 86) habla de paradigma débil.

${ }^{33}$ Tal como lo señala Bravo (2009, p. 56), "la relación entre el eîdos y los individuos que lo contienen es concebida en nuestro diálogo <, el Menón>, como la que existe entre el universal y lo particular y solo a este título es eîdos sinónimo de ousía".

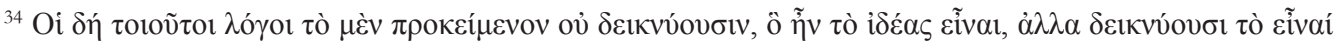

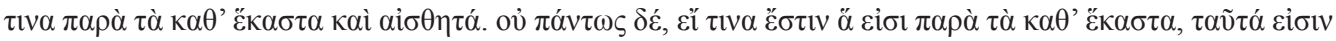

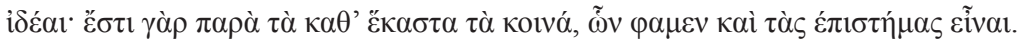

${ }^{35}$ Reshotko (1997, p. 123) cree ver el argumento a partir de las ciencias en el Cratilo, diálogo en el cual la mayoría de los intérpretes acuerdan que no hay presencia de la teoría de las Ideas.
} 
propiedad común que responda a la pregunta qué es $\mathrm{X}$, o sea, cuál es la esencia de $\mathrm{X}$, pero la existencia de Ideas, esto es, de entidades transcendentes, no es deducible de él. Esto es lo que señala Aristóteles cuando sostiene que el argumento basado en las ciencias no sirve para probar las Ideas, ya que por un lado prueba poco y por otro lado mucho.

\section{Argumento de las Ciencias en el fragmento 48}

El Protréptico de Aristóteles es una exhortación a la filosofía. En esta obra, Aristóteles intenta persuadir al auditorio de que si bien la filosofía es un bien en sí mismo (fragmentos 4244), tiene una gran utilidad (46-50). Al querer defender esta última tesis, el estagirita establece una relación entre filosofía y política mediante la cual pretende demostrar que el legislador para gobernar justamente y dictar buenas leyes para su ciudad debe conocer la verdad y naturaleza del alma (fragmento 46). En este contexto, en el fragmento 48, Aristóteles dice:

Pero esto no es capaz de hacerlo quien no ha cultivado la filosofía y no ha conocido la verdad. Y, en las demás artes, no alcanzan el saber integramente, al no obtener los instrumentos y los razonamientos más exactos de objetos primeros en sí mismos, sino de objetos segundos, terceros o aún más alejados, y extraen sus razonamientos de la experiencia. A diferencia de los demás, solo en el caso del filósofo tiene lugar la imitación a partir de objetos exactos en sí mismos. Pues él los contempla en sí mismos y no sus imitaciones (Jámblico Protréptico 55. 6-14. Trad. Vallejo Campos). ${ }^{36}$

Desde la perspectiva del estagirita, el que conoce ap’ autôn tôn akribôn conoce lo que es en sí mismo y, por lo tanto, sabe cuál es la naturaleza de las cosas. ${ }^{37}$ Esta descripción del

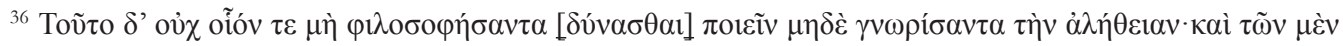

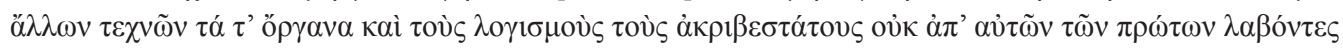

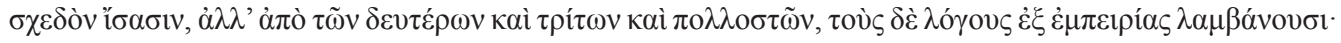

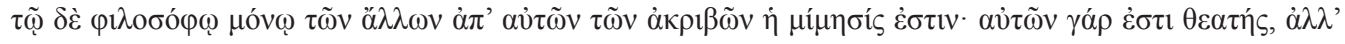

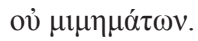

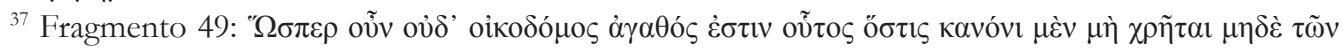

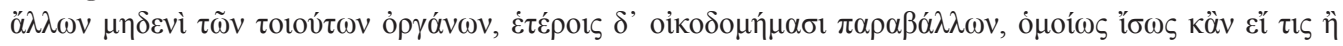

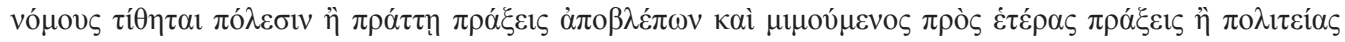

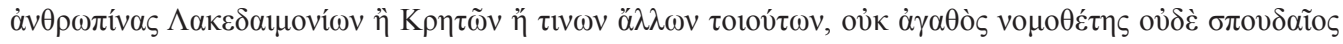

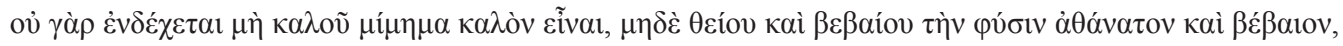

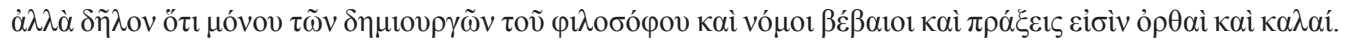
"Así pues, igual que no es buen constructor el que no utiliza la regla o ninguno de los demás instrumentos de esta clase, sino que se deja llevar por otras construcciones, de manera semejante, si alguien instituye leyes para las ciudades o actúa considerando e imitando otras acciones o constituciones humanas de lacedemonios, cretenses o de cualquier otra ciudad por el estilo, no es un legislador bueno ni riguroso. Efectivamente, no puede ser bella una imitación de lo que no es bello, ni puede ser de naturaleza inmortal y estable la imitación de lo que no es divino ni estable, pero evidentemente el
} 
conocimiento constituye el punto álgido del discurso aristotélico y, por este motivo, el objeto de debate entre los estudiosos, principalmente entre aquellos que quisieron ver la posible presencia de la teoría platónica de las Ideas. ${ }^{38}$ Este debate ha abierto dos líneas interpretativas. Quienes han sostenido que Aristóteles había pasado por un período platónico ven en este pasaje la clave para apoyar su tesis. En este sentido, es clásica la postura de Jaeger. Para Jaeger, "las primeras cosas no pueden aludir al universal abstracto en el sentido posterior de Aristóteles, porque lo universal abstracto no se pone en contraste con imitaciones de ninguna especie. Imitaciones es de nuevo un término específicamente platónico, que no puede usarse con sentido independiente de la doctrina de que las formas son arquetipos" 39

En las antípodas de esta interpretación se encuentran los análisis realizados por autores como Düring y Chroust. Para estos intérpretes, si bien Aristóteles estaría utilizando un vocabulario platónico, el contenido del discurso es netamente aristotélico. Desde la perspectiva de Düring, ${ }^{40}$ dado que el Protréptico era una obra de divulgación, dirigida al público en general, carecía del lenguaje técnico. Por este motivo, términos como eîdos, mímesis, autó y agathón no deben interpretarse bajo el sentido técnico platónico, sino como un lenguaje que, si bien era de uso común en la Academia, tenía como referente concepciones netamente aristotélicas. ${ }^{41}$ Por nuestra parte, intentaremos mostrar que este vocabulario también es empleado por Aristóteles a lo largo del corpus para hacer referencia a concepciones que no son platónicas. Con esto pretendemos dar un paso más en la interpretación de Düring, que considera que es lenguaje platónico pero que las concepciones allí defendidas son aristotélicas.

En este sentido, resulta relevante tener en cuenta que en los fragmentos precedentes (42-44), citados por Jámblico inmediatamente antes que la serie 47-50, Aristóteles señala que quien confunde las cosas buenas con las útiles no distingue lo que es buscado por sí mismo y, por lo tanto, no diferencia aquello que es un fin en sentido estricto de lo que es un mero medio para obtener dicho fin. Tal individuo "no se parece en nada a quien sabe lo que es bello y bueno ni a quien puede discernir entre causa y concausa" (fragmento 42). Teniendo en cuenta este contexto, podemos inferir que lo que quiere decir Aristóteles en los fragmentos 47-48 es que el político obtiene leyes que son buenas cuando se basa en el conocimiento de lo que es bueno en sí mismo. ${ }^{42}$ Ahora bien, esto no nos autoriza a hablar de presencia de

filósofo es entre los artesanos el único que logra leyes estables y acciones rectas y bellas" (Jámblico, Protréptico X 54. 14-25).

${ }^{38}$ Tal como lo indica Vallejo Campos (2005, p. 184), el fragmento 48 “está impregnado de un lenguaje con claras resonancias platónicas: aídios (eterno, B 50; cf. Timeo 29a3-5), mónimos (permanente, B 50) y bébaios (estable, B 49; en Symp 184b3 y Crát. 411c3 aparecen ambos términos juntos), junto con el concepto de mímesis (imitación), parecen situarnos de lleno en el contexto de la teoría platónica de las formas. Sin embargo, nada puede concluirse con seguridad de todo ello".

${ }^{39}$ Jaeger, W. (1993, p. 111).

${ }^{40}$ Düring (1961, p. 218).

${ }^{41}$ Düring (1961, p. 220).

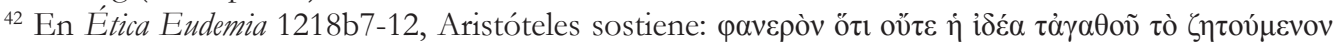

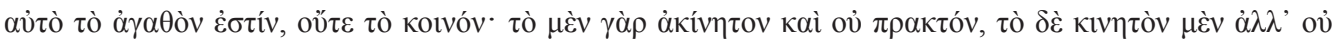


la teoría de las Ideas en el Protréptico. Por tal motivo, al referirse a las imitaciones, tampoco estamos autorizados a sostener que Aristóteles presupone al binomio copia/Idea que la teoría platónica supone. Por tal motivo, en lo que resta del trabajo intentaremos establecer qué quiere indicar Aristóteles mediante la expresión "en sí mismos” y el término imitaciones.

\section{III.1. Lo QUE ES EN SÍ O POR Sí EN EL FRAGMENTO 48}

En el fragmento 48 Aristóteles afirma que para promulgar leyes justas no alcanza con conocer las constituciones de otras póleis (fragmento 49), esto es, lo particular y contingente, sino que se debe conocer el principio de la acción, identificado con el bien del hombre, y, por este motivo, con su fin último. Esta lectura, nos lleva a pensar que en dicho fragmento del Protréptico Aristóteles presupone el argumento basado en la ciencia presentado en Sobre las Ideas. En esta última obra Aristóteles dice:

Además, si la medicina es ciencia no de esta salud en particular sino de la salud en sentido absoluto, habrá cierta salud en sí; y si la geometría no es ciencia de este caso de lo igual y de lo conmensurable en particular sino de lo igual y de lo conmensurable en sentido absoluto, habrá cierta igualdad en sí y cierta conmensurabilidad en sí, y éstas son las Ideas. (Alejandro de Afrodisias, Comentario a la Metafísica 79, $11-15) \cdot{ }^{43}$

En el Protréptico, Aristóteles parte de dos supuestos, uno implícito y otro explícito. El primero, el implícito, es que existe una ciencia política cuyo fin es el bien para la pólis (fragmentos 46-50). El otro supuesto, el explícito, es que el que quiere gobernar correctamente tiene que tener leyes buenas, bellas y justas. Ahora bien, por las razones antes referidas, a saber: no hay conocimiento de lo particular y contingente (fragmento 48), el objeto de tal ciencia, al igual que en Sobre las Ideas en relación con la medicina o la geometría, no podrá ser simplemente el conocimiento de las cosas bellas o justas, o de leyes bellas o justas, sino de lo bello y de lo justo en sí. ${ }^{44}$ La pregunta que surge es la siguiente: ¿qué debemos entender en este pasaje por "lo que es en sí"?

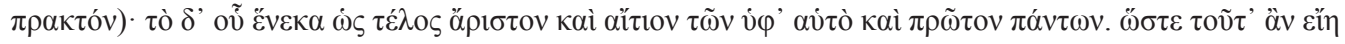

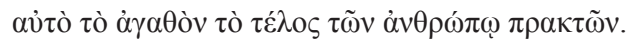

"Es evidente, pues, que el bien en sí que buscamos no es ni la Idea del bien, ni el bien común (pues uno es inmóvil e irrealizable, otro, móvil, pero tampoco realizable). Pues aquello con vistas a lo cual se persigue algo como fin, es lo mejor y causa de los bienes subordinados, y el primero de todos; de manera que esto sería el bien en sí, el fin de todas las acciones humanas."

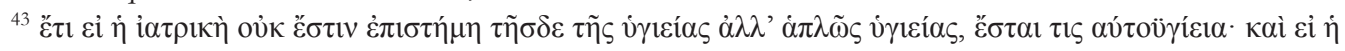

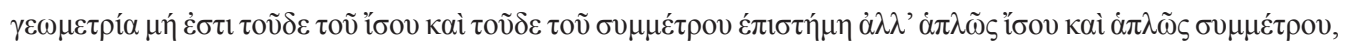

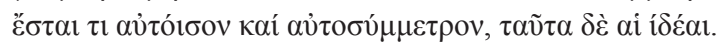

${ }^{44}$ Fragmentos 48 y 49 del Protréptico. 
Es correcto decir que las Ideas platónicas son por sí mismas en tanto que dan cuenta de las características de las cosas y permiten conocerlas, pero no requieren de otra cosa para ser o ser explicadas. Sin embargo, no hay elementos concluyentes que nos permitan sostener que en el Protréptico Aristóteles haya sostenido la teoría de las Ideas. El uso de las expresiones "en sí mismo" y "por sí mismo" tampoco es un elemento suficiente para defender tal tesis. El análisis de algunos pasajes del corpus aristotélico nos permite notar que Aristóteles usa los calificativos "lo es por sí mismo" o "en sí mismo" para caracterizar tanto a la ousía como a los primeros principios y causas. En Metafísica V 1 1003a 25-27, Aristóteles afirma "puesto que buscamos los principios y las causas supremas, es evidente que estas han de serlo necesariamente de alguna naturaleza por sí misma" (trad. Calvo Martínez). ${ }^{45}$ En Metafísica VII 4 1029b Aristóteles describe la esencia mediante el calificativo de "lo que

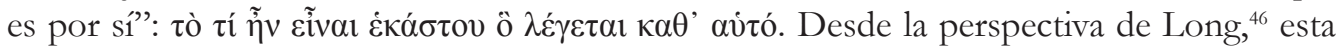
identificación implica que el ser para algo está vinculado con su ểdos, el cual se identifica

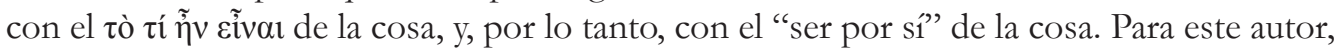
a diferencia del platonismo, con Aristoteles se abre el espacio para comprender el eîdos como perteneciendo en sí mismo y verdaderamente a la cosa. ${ }^{47}$ Leído de esta forma, aquello que es per se es "aquello en virtud de lo cual", razón por la cual es prioritariamente la forma o entidad o "lo que es ser". 48

En Metafísica III 4, 999a 25-28, al formular la octava aporía, Aristóteles señala la siguiente problemática:

Hay una aporía relacionada con estas, la más difícil de todas y la que es más necesario considerar, de la cual trataremos ahora. Y es que, si no existe algo aparte de los individuos y los individuos son infinitos, ¿cómo es posible alcanzar ciencia de las cosas infinitas? En efecto, conocemos todas las cosas en la medida en que se da algo que es uno, idéntico y universal (Trad. Calvo Martínez). ${ }^{49}$

Este pasaje de la Metafísica es la versión aporética de la formulación del argumento que parte de las ciencias presentado en Sobre las Ideas. En este capítulo del libro III Aristóteles se enfrenta con la problemática de si existe algo además de las infinitas cosas sensibles, pues de negar la existencia de ese algo nos enfrentamos a dos consecuencias inaceptables: 1) no existiría conocimiento al menos que se lo identifique con la percepción (Metafísica III 4 999b 4-5) y 2) no existirían los particulares sensibles, pues no habría generación (Metafísica III 4

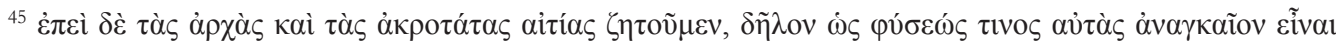

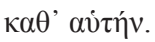

${ }^{46}$ Long (2011, p. 180).

${ }^{47}$ Long (2011, p. 182).

${ }^{48}$ Owen (1963, p. 349).

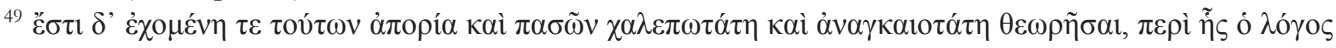

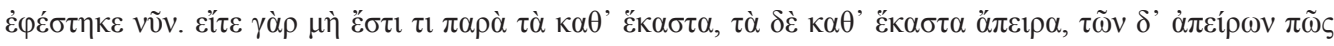

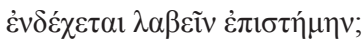


999b 6-8) y lo sensible es aquello que necesariamente está sujeto a la generación y corrupción. Ahora bien, Aristóteles descarta que esto que es eterno, uno e imperecedero pueda ser el género o universal, si por esto entendemos las Ideas platónicas. No obstante, al partir de los mismos supuestos epistémicos defendidos por Platón, debe dar respuesta a esta problemática, ya que, de lo contrario, debería aceptar la negación de su propia concepción de ciencia y la existencia de aquello que él mismo pretende explicar: lo real. Esta encrucijada presupuesta en el argumento a partir de las ciencias lo llevará a afirmar unas líneas más abajo:

En efecto, necesariamente es algo lo que se genera y aquello a partir de lo cual se genera, y el último de estos es ingenerado, si es que ha de pararse en algún punto y no es posible la generación a partir de lo que no es. Además, puesto que hay generación y movimiento, necesariamente han de tener límite. ( $Y$ es que ningún movimiento es infinito, sino que todos tienen fin, y no es posible que se genere lo que no puede llegar a estar generado; y por su parte, lo generado existe tan pronto como se generó.) Además, si la materia es (eterna) por ser ingenerada, mucho más razonable aun es que (lo) sea la entidad a que aquella llega en la generación. Y si no lo son ni esta ni aquella, nada existirá en absoluto; pero si esto es imposible, necesariamente habrá algo fuera del compuesto concreto: la forma y la configuración específica (Metafísica III 4, 999b 6-16. Trad. Calvo Martínez). ${ }^{50}$

La conclusión a la cual pretende arribar Aristóteles es que hay algo que debe ser ingenerado y eterno y eso será la causa de las cosas generadas y, aunque no lo diga explícitamente en el pasaje, el objeto de la ciencia. Para mostrar tal tesis, parte de las siguientes premisas:

1. no es posible la generación a partir del no ser;

2. la existencia de la generación y el movimiento es una evidencia;

3. la generación debe tener un límite, pues, si todo fuese generado, habría una regresión al infinito.

Sobre la base de estas premisas, Aristóteles concluye que, si la materia es eterna pues es ingenerada, más aún debe serlo la ousía. Para garantizar la existencia de los sensibles y el conocimiento debe haber algo no generado, que sea en acto, que le dé a la cosa su configuración específica y que sea su fin, es decir, debemos presuponer la ousía, entendiendo por esto su configuración conceptual o formal. De esta manera, lo que es uno, eterno,

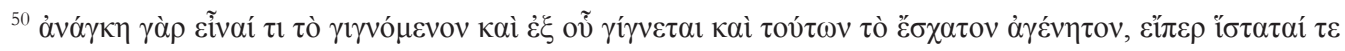

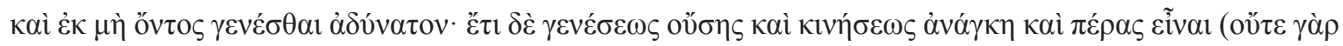

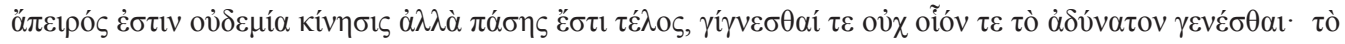

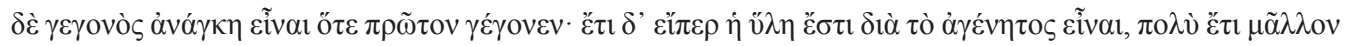

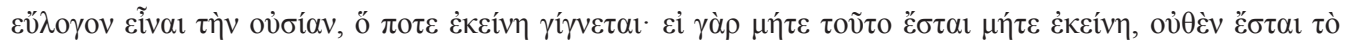

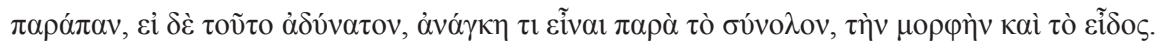


ingenerado y condición de posibilidad de conocimiento por ser primero, en sí y por sí, es la forma o configuración conceptual de la cosa.

En el fragmento 33 del Protréptico (Jámblico Protréptico 38.22-39.4) Aristóteles presenta un argumento parecido al esgrimido en el fragmento 48, que va en la misma línea que los pasajes citados de Metafisica:

Siempre, efectivamente, es más cognoscible lo anterior que lo posterior y lo mejor por naturaleza que lo peor. Pues hay ciencia más de lo definido y ordenado que de sus contrarios, y más de las causas que de los efectos. Las cosas buenas son más definidas y ordenadas que las malas, igual que lo es más el hombre virtuoso que el deshonesto. Es necesario, efectivamente, que haya entre unas y otras cosas la misma diferencia. Y lo anterior es causa en mayor medida que lo posterior, porque, si suprimimos aquello, se suprime lo que recibe su realidad de ello: las líneas, si se suprimen los números; las superficies, si se suprimen las líneas; los volúmenes si se suprimen las superficies; y las llamadas sílabas si se suprimen las letras. ${ }^{51}$ (trad. Vallejo Campos, levemente modificada)

En este fragmento, Aristóteles señala que la ciencia debe ser de lo que es anterior, esto es, de las causas y de los elementos constitutivos de las cosas, ya que además de ser por sí, esto es, no necesitar de nada ulterior para ser explicados, son aquello por lo cual se da cuenta del ser y del conocimiento del resto de las cosas. Líneas más abajo, al sostener que las cosas buenas son más definidas y ordenadas que las malas, Aristóteles identifica a las primeras con lo anterior y las causas. El paralelismo establecido entre lo anterior y las causas con aquello por cuyo medio las cosas reciben su ser, nos permiten concluir que, si la relación entre la noción de causa y la de bien es correcta, el bien es, al menos, una de las causas por la cuales las cosas reciben su ousía, y, por lo tanto, su ser. Esto no implica aceptar que el bien es un principio en el mismo sentido en que lo es la Idea platónica del Bien. Por el fragmento 42,52

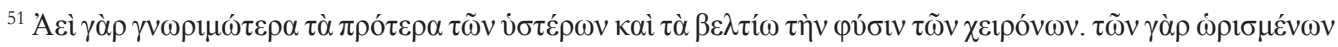

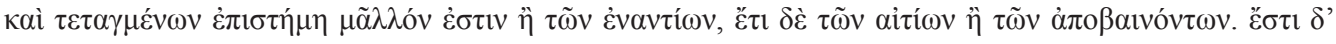

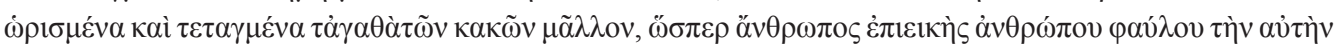

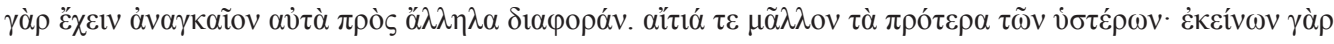

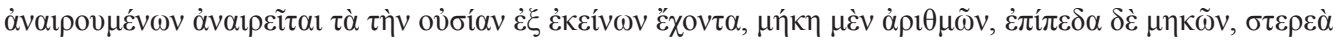

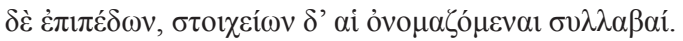

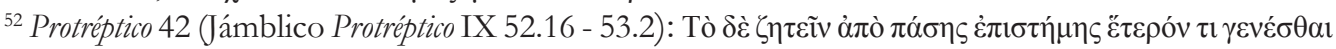

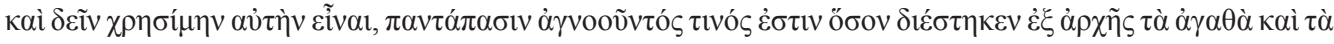

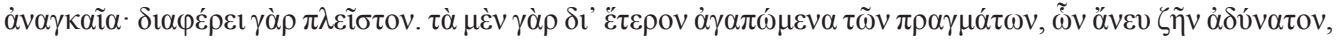

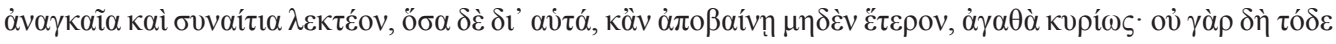

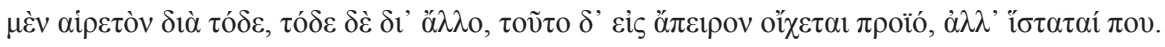

"Pretender que toda ciencia produzca algo distinto < respecto de ella misma $>$ y que sea útil es propio de alguien que desconoce absolutamente en qué medida se separan desde su origen las cosas buenas y las cosas necesarias. Pues se diferencian en grado sumo. En efecto, las cosas que deseamos
} 
sabemos que el bien es la verdadera causa de las cosas, y este se identifica con su fin. Cada cosa tiene un bien que le corresponde por naturaleza y se plenifica en tanto existe conforme a él. Dado esto, las causas mencionadas en el fragmento 33 deben ser aquello que es "en sí mismo" en el fragmento 48, ya que en uno y otro caso se está hablando de la misma ciencia. En ambos casos, se podría tratar de una remisión al bien como principio rector de la acción, que solo el filósofo conoce, pues solo él ha estudiado la naturaleza humana (fragmento 46).

Si aceptamos lo afirmado hasta aquí, podemos concluir que la confrontación entre el Protréptico y Sobre las Ideas es una prueba relativamente solida de que las objeciones que Aristóteles realiza a la teoría platónica a través del argumento de las ciencias se aplicarían al fragmento 48 y a quienes sostienen tal tesis, si se persiste en creer que allí se postula la misma teoría. Simultáneamente la existencia de un argumento para refutar las razones por las cuales los platónicos defienden la existencia de las Ideas en paralelo a la redacción del Protréptico permite sostener que Aristóteles no podría defender dicha teoría, pues de lo contrario habría caído en una inconsistencia.

\section{III.2. "Lo que es en sí"/Imitaciones en el fragmento 48 del Protréptico}

Uno de los principales problemas hermenéuticos que presenta el fragmento 48 del Protréptico es la aparente contraposición que Aristóteles realiza entre "lo que es en sí" y las imitaciones. Sin embargo, creemos que la clave para comprender el sentido del texto es dada por Aristóteles en el fragmento 47, citado por Jámblico (Protréptico X 54. 22-55.6) inmediatamente antes que el fragmento 48:

Efectivamente, así como en las demás técnicas productivas los mejores instrumentos se han descubierto a partir de la naturaleza - por ejemplo, en la construcción la plomada, la regla o el compás, los hemos obtenidos de <las observación $>$ del agua, la luz y los rayos del sol, que nos sirve como criterio para comprobar lo que es suficientemente recto y plano desde el punto de vista perceptivo -, de la misma manera el político también debe estar en posesión de ciertas normas derivadas de la naturaleza en sí misma y de la verdad, en referencia a las cuales juzgue qué es justo, bello y conveniente. Pues igual que allí estos instrumentos superan a todos los demás, también la mejor ley es la que mejor concuerda con la naturaleza (Jámblico Protréptico 54.22-55.6). ${ }^{53}$

\footnotetext{
para la realización de otras y sin las cuales es imposible vivir son necesarias y causas concomitantes, mientras que las que son deseadas por ellas mismas y no resulta de ellas otra cosa son buenas, pues no es deseable por esto ni por otra cosa y prosigue al infinito, sino que la serie se detiene en alguna parte" (Trad. Vallejo Campos).

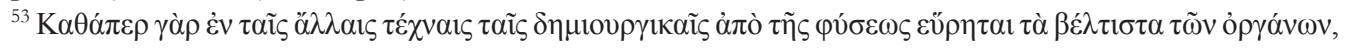

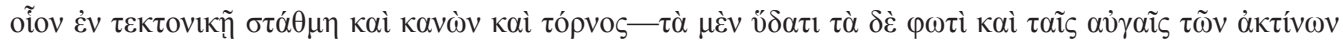

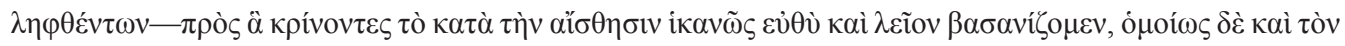


Lo que nos interesa de este fragmento es la descripción de cómo las técnicas obtienen sus instrumentos observando el comportamiento de la naturaleza. Para construir la plomada, la regla o el compás, los hombres no se han valido de otros instrumentos ya existentes, sino que lo hicieron a partir del conocimiento del comportamiento del agua, la luz y los rayos del sol. Si bien actúan por imitación, lo que imitan es la naturaleza. Este modus operandi le sirve a Aristóteles para sostener que el político debe proceder de modo análogo a estas técnicas. El político gobierna por medio de sus leyes y normas. En este sentido las leyes son al político lo que la plomada y la regla para las técnicas: sus instrumentos. La analogía sirve para mostrar que, así como las técnicas productivas deben tener como modelo a la naturaleza para realizar sus instrumentos, el político debe proceder del mismo modo, ${ }^{54}$ pues no se puede hacer una ley sobre la base de otras leyes, que son múltiples, variadas y contingentes. Debe tener como criterio el conocimiento de lo que es el bien para el hombre, razón por la cual debe conocer su naturaleza. En este sentido es relevante señalar que en el fragmento 48 Aristóteles no realiza una verdadera contraposición entre conocimiento de lo que es en sí/ imitaciones, sino que afirma que solo el filósofo puede obtener imitaciones a partir de lo primero en sí mismo. Si seguimos la línea de lectura arriba señalada y continuamos sosteniendo que las imitaciones son las leyes que reflejan los principios de la acción, esto es, los verdaderos fines y, por ende, bienes del hombre, lo que Aristóteles está afirmando en este fragmento es que solo por medio del filósofo las leyes de la pólis pueden ser acordes a lo más exacto en sí, esto es, conforme al verdadero bien del hombre ${ }^{55}$ y no copias o réplicas de leyes de otras ciudades. Que el político obre de este modo sería tan incorrecto como que el constructor realice casas mirando construcciones ya realizadas, pero no utilizando los instrumentos correspondientes y, por lo tanto, los criterios adecuados: aquellos de la construcción (fragmento 49). Si se acepta esta lectura, lo que está en la base del fragmento 48 no necesariamente tiene que ser la contraposición entre las Ideas y las imitaciones, sino el axioma aristotélico, tan presente a lo largo de todo el Protréptico, de que la técnica imita a la naturaleza (fragmentos 13, 14 y 23) y la completa. "La naturaleza en su totalidad, como si estuviera dotada de razón, no hace nada al azar, sino todo con vistas a algo, y, desterrando el azar, la naturaleza atiende al fin más incluso que las técnicas, porque también las técnicas eran imitaciones de la naturaleza" (trad. levemente modificada de Vallejo Campos). ${ }^{56} \mathrm{Si}$ bien la política es una ciencia práctica y no una técnica, el paragón sirve para hacer inteligible el modo de proceder análogo a partir de un ejemplo claramente entendible para el interlocutor. Mediante los ejemplos utilizados

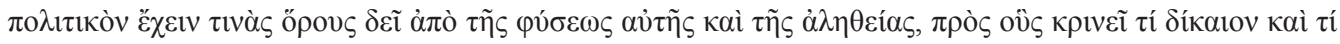

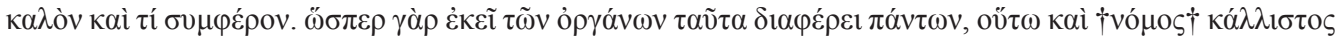

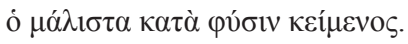

${ }^{54}$ Véase Zannata (2008, p. 297).

${ }^{55}$ Según Berti (2005, p. 411), al hablar de agathón en el Protréptico, Aristóteles no está aludiendo ni a un principio trascendente ni a un juicio subjetivo, sino al principio de un orden objetivo, identificado con la naturaleza. El bien de cada cosa sería, en este sentido, el cumplimiento de su naturaleza y, por este motivo, de su fin.

${ }^{56}$ Fragmento 23 (Jámblico Protréptico 34. 6-9) 
en los fragmentos 47 y 48 Aristóteles realiza un doble movimiento. Por un lado, en el fragmento 47 enfatiza la necesidad de que en la obtención de las leyes los políticos procedan de manera análoga a las técnicas mirando el comportamiento de su objeto de estudio. Pero, por otro lado, en el fragmento 48 señala un déficit de estas técnicas respecto de la filosofía, que muestra un límite en relación con su modo de proceder. En este fragmento, Aristóteles indica que, mediante sus instrumentos (la regla, la plomada, etc.), los que se ocupan de las técnicas pueden acceder a determinadas características de su objeto, aquellas que les son dadas de forma inmediata, esto es, sus cualidades sensibles, razón por la cual no tienen conocimiento en sentido propio (Metafísica I 1). Si no trascienden esta instancia, sólo tendrán razonamientos de segundo orden, pero no alcanzarán los principios de las cosas, aquellos que determinan qué son. En este sentido, si aceptamos que en el fragmento 48 Aristóteles continúa argumentando en la misma línea que en el fragmento precedente, podemos pensar que a través del término mímesis no está aludiendo a la relación entre los principios y las cosas que son por participación o imitación de dichos principios, sino al modo de proceder propio de las técnicas aludidas por el estagirita. En consecuencia, podríamos concluir que, si bien la presencia de cierto bagaje platónico en los fragmentos 48 y 47 es indudable, esta influencia parece estar vinculada con el modo en que se explica lo real apelando a ciertos principios que trascienden lo sensible y a la definición de la ciencia como el conocimiento de dichos principios. Pese a esto, al analizar la naturaleza de dichos principios en ambos pensadores, no parece haber elementos que nos permitan concluir que Aristóteles esté postulando en el fragmento 48 o en algún otro fragmento del Protréptico la teoría platónica de las Ideas.

\section{Conclusiones}

En el presente trabajo hemos querido demostrar que el fragmento 48 no puede usarse como un testimonio en favor de que Aristóteles haya sostenido la teoría de las Ideas. A tales fines nos hemos valido de dos recursos diferentes. Uno de estos recursos, que ha sido el empleado por la tradición exegética, consistió en demostrar que las obras en las cuales Aristóteles ha realizado la crítica a la teoría de las Ideas, sobre todo, Sobre la Ideas y Sobre la filosofía o Metafísica I, son relativamente contemporáneas al Protréptico. La datación en un mismo período de estos escritos nos permitió inferir que, de afirmar que Aristóteles habría sostenido la teoría de las Ideas, se debe aceptar una inconsistencia en su pensamiento, pues, al mismo tiempo que criticó dicha teoría, la defendió. Sin embargo, esta estrategia argumentativa no nos resultó suficiente para defender nuestra tesis. Por tal motivo, nuestra estrategia hermenéutica fue intentar demostrar que los que creen que Aristóteles defendía en el Protréptico la teoría de las Ideas caen en la misma crítica que el estagirita realiza a los platónicos cuando estos dan los argumentos de por qué deben existir las Ideas. En ambos casos, concluyen más de lo que el texto permite concluir. Esto se debe básicamente a que quienes sostienen que hay presencia de la teoría de las Ideas en el Protréptico basan su tesis en que en este texto Aristóteles habla de "lo que es en sí mismo" y de imitaciones. Hemos intentado demostrar que, si bien esto es un vocabulario platónico, también Aristóteles usa las mismas expresiones y los mismos términos para presentar concepciones propias. En los 
escritos éticos promulga la existencia de un bien en sentido absoluto o el bien en sí (Ética Eudemia I 8, 1217b 3-5), en la Metafísica alude explícitamente a la ousía como aquello que es por sí (Metafísica VII 4 1029b) y, paralelamente, se refiere a las técnicas como aquello que imita la naturaleza (Protréptico fragmentos 11, 13 y 47). Presuponer sobre la base del uso terminológico que Aristóteles sostiene la teoría de las Ideas, teniendo en cuenta que él utiliza esa terminología en la exposición de sus propias concepciones, es pretender que el texto diga más de lo que por sí mismo dice. La definición de ciencia propuesta en los fragmentos 33 y 48 no llevan a concluir que las leyes no pueden ser promulgadas como imitaciones de otras leyes o sobre lo que a cada uno le parece bueno. Hay ciertos principios que deben ser tenidos en cuenta como criterios. Sin embargo, dichos principios no son las Ideas platónicas. Para Aristóteles el bien es el criterio adecuado de la acción, es por sí y responde a la naturaleza de la cosa (fragmento 42), razón por la cual puede ser el principio de la acción presupuesto en el fragmento 48. Por esta razón suponer que lo que es “en sî" en el fragmento 48 son las Ideas es claramente concluir más de lo que el texto permite.

\section{REFERENCIAS}

\section{EDICIONES Y TRADUCCIONES}

BERTI, E. Protreptico. Introduzione, traduzione e commento di E. Berti. Milano: UTET, 2008 [2000].

CASAGLIA, M. Aristotele. Protreptico. Introduzione, traduzione e commento di M. Casaglia. Firenze: Editrice Clinamen, 2001.

CHROUST, A. H. Aristotle's Protrepticus. Introduction, reconstruction and comments by A. H. Chroust. Indiana: University of Notre Dame Press, 1964.

DÜRING, I. Aristotle’s Protrepticus, An attempt at reconstruction. Göteborg: Almqvist \& Wiksell, 1961.

ROSE, V. Aristotelis qui ferebantur Librorum Fragmenta. Stuttgart: Teubner, 1966

ROSS, W. D. Aristotelis dialogorum Fragmenta. Oxford: Clarendon Press, 1964.

ROSS, W. D. (ed.) The Works of Aristotle translated into English. Oxford: Clarendon Press, 1908-52.

SCHNEEWEISS, G. Aristoteles, Protreptikos. Rekonstruiert, übersetzt und kommentiert von G. Schneeweiss. Darmstadt: Wissenschaftliche Buchgesellschaft, 2005.

VIANO, C. A. Aristotele, Metafisica. Introduzione, traduzione e commento di C. A. Viano. Torino: Unione Tipografico- Editrice Torinese, 1980.

ZANATTA, M. Aristotele. Frammenti. Opere logiche e filosofiche. Introduzione, traduzione e commento di M. Zanatta. Milano: BUR, 2010.

ZANATTA, M. Aristotele, I Dialoghi. Introduzione, traduzione e commento di M. Zanatta. Milano: Biblioteca Universitaria Rizzoli, 2008. 


\section{REFERENCIA SECUNDARIA}

AUBENQUE, P. El problema del ser en Aristóteles. Trad. cast. de V. Peña. Madrid: Escolar y Mayor Editores, 2008.

BERTI, E. La filosofia del "primo" Aristotele. Milano: Centro di Richerche di Metafisica dell' Università Cattolica del Sacro Cuore, 1997 [1962].

BERTI, E. Aristotele, dalla dialettica alla filosofia prima. Milano: Bompiani, 2004 [1977].

BERTI, E. Nuovi studi aristotelici. Brescia: Morcelliana, 2005.

BIGNONE, E. L' Aristotele perduto e la formazione filosofica de Epicuro. Firenze: La Nuova Italia, 1973. $2 \mathrm{v}$.

CASE, T. Aristotle, en Wians, W. (ed.). Aristotle's philosophical development. London: Rowman \& Littlefield, 1996. p. 1-40.

BRAVO, F. Teoría de la definición en el Menón. In: CORREA MOTTA, A.; ZAMORA, J. M. (eds.). Eunoia. Estudios de filosofía antigua. Bogotá: Universidad Nacional de Colombia, 2009, p. 49-84.

CARDULLO, R. L. "Il Perì ideôn di Aristotele e il Parmenide di Platone, ovvero: da un comune tentativo di 'salvare' le idee verso un inevitabile scontro dottrinale". In: BARBANTI, M.; ROMANO, F. (ed). Il Parmenide di Platone e la sua tradizione, Atti del III Colloquio Internazionale del Centro di Ricerca sul Neoplatonismo. Catania: CUECM, 2002, p. 155-184.

CHERNISS, H. Aristotle's criticism of Plato and the Academy. Baltimore: Johns Hopkins Press, 1944.

FINE, G. On Ideas. Aristotle's criticism of Plato's theory of forms. Oxford: Clarendon Press, 1995.

GUTHRIE, W. Historia de la filosofía griega. Trad. cast. de A. Medina González. Madrid: Gredos, vol. VI, 1993 [1981].

JAEGER, W. Aristóteles. Bases para la historia de su desarrollo. Trad. cast. de J. Xirau y W. Roce. México: Fondo de Cultura Económica, 1993 [1923].

HUGHES, G. J. Aristotle on Ethics. London: Routledge, 2003 [2001].

LONG, C. P. Aristotle on the nature of truth. New York: Cambridge University Press, 2011.

MOHR, R. D, Plato, "Statesman" 284c-d: An "Argument from the sciences" Author(s). Phronesis, v. 22, n. 3, p. 232-234, 1977.

OWEN, J. The doctrine of being in the aristotelian Metaphysics. Toronto: Pontifical Institute of Mediaeval Studies, 1963.

PETRILLI, R. Linguaggio e filosofía nella Grecia antica. Roma: Edizioni di Storia e Letteratura, 2009. 
REALE, G. The concept of first philosophy and the unity of the Metaphysics of Aristotle. New York: State University of New York, 1980 [1967].

RESHOTKO, N. "A Bastard kind of reasoning: The argument from the sciences and the introduction of the receptacle in Plato's Timaeus". History of Philosophy Quarterly, v. 14, n. 1, p. 121-137, 1997.

ROSS, D. Teoría de las ideas de Platón. Trad. de José Luis Diez Arias. Madrid: Cátedra, 1993 [1951].

VOGEL, C. J. “The legend of the platonizing Aristotle”. In: DÜRING, I.; OWEN, G.E. L. (ed). Aristotle and Plato in the mid-Fourth century. Göteborg: Almqvist \& Wiksell, 1960, p. 248-256.

Recebido em: 13 de fevereiro de 2017 Aprovado em: 14 de março de 2017 